\title{
ESCENA
}

Publicación semestral. ISSN 2215-4906

Volumen 80 - Número 1

Julio - Diciembre 2020

\section{Meyerhold: un precursor de la Estética de la recepción}

\author{
Meyerhold: A pioneer in Reception Aesthetics
}

\author{
Manuel F. Vieites
}

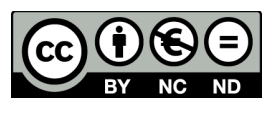

Esta obra está bajo una licencia Creative Commons Reconocimiento-No comercial-Sin Obra Derivada 
Artículo

\title{
Meyerhold: un precursor de la Estética de la recepción
}

\author{
Meyerhold: A pioneer in Reception Aesthetics
}

\author{
Manuel F. Vieites ${ }^{1}$ \\ Universidad de Vigo \\ España
}

Recibido: 30 de marzo de 2019 Aprobado: 05 de julio de 2019

\section{Resumen}

En el primer cuarto del siglo XX y frente a las tendencias dominantes del teatro burgués, cobran fuerza dos tendencias artísticas antitéticas que persiguen objetivos antagónicos: la que apuesta por la re-teatralización de la escena y la que opera en la des-teatralización. Meyerhold se sitúa en la primera, y en ella, tanto desde sus espectáculos como en sus escritos teóricos, formula un conjunto de principios fundamentales en la comprensión de la comunicación teatral y en la consideración de las funciones del director de escena que lo convierten en un pionero de las teorías de la recepción. Un aserto que pretendemos probar con este trabajo, elaborado a partir de una revisión de su obra teórica y de literatura científica especialmente relevante. Como conclusión, destacamos la relevancia de las propuestas de Meyerhold para reconstruir un teatro que, asentado en la razón crítica, sivva para la construcción de una recepción igualmente crítica.

Palabras clave: constructivismo; teatro; comunicación; vanguardia; teoría crítica

1 Profesor y director de la Escuela Superior de Arte Dramático de Galicia, España. Profesor Asociado de la Universidad de Vigo. Doctor en Filosofía y Ciencias de la Educación. ORCID: 0000-0003-43726234. Correo electrónico: mvieites@uvigo.es

ESCENA. Revista de las artes, 2020, Vol. 80, Núm. 1, pp. 69-95 ISSN 2215-4906 


\begin{abstract}
In the first quarter of the 20th century, two antithetical artistic trends gain importance, both confronting the dominant tendencies of the bourgeois theatre and both pursuing antagonistic objectives. One trend defends a necessary re-theatricalization, while the other bets for a radical de-theatricalization. Meyerhold positions himself in the first trend, for all his theatrical creations and theoretical writings, he formulates a set of fundamental principles and in the understanding of theatrical communication for the consideration of the functions of the stage director, and in doing so, he becomes a pioneer in the field of reception aesthetics. We intend to demonstrate such a claim with this paper, written after a review of scientific literature, which also includes his personal contributions. As a conclusion, we highlight the transcendence of Meyerhold's proposals to promote a theatre that, based on critical theory, could help to encourage a reception equally critical.
\end{abstract}

Keywords: Constructivism; theater; communication; avant-garde; critical theory 


\section{Presentación ${ }^{2}$}

Hace poco más de cien años, en Europa, se vive un debate entre dos tendencias artísticas, filosóficas e incluso ideológicas, que marcan el desarrollo de la escena en el siglo XX y en los inicios del XXI. Por un lado, un grupo de artistas, en esencia futuristas o dadaístas, anclados en el paradigma de lo que será la postmodernidad, buscan des-teatralizar el teatro, con propuestas sobre las que emerge el movimiento de las artes de la acción o de la presentación escénica (happening y performance en inglés), así como todo el teatro posmoderno actual, con sus variantes y divergencias (Birringer, 1991; Carlson, 1996; Schechner, 2002). Un movimiento que asienta su discurso en el agotamiento del teatro como forma artística (Lepecki, 2006) y propone convertir la escena en un espacio de confluencia de diversas manifestaciones, al dar lugar a formas nuevas, marcadas por la heterogeneidad, el collage, la mixtura, la hibridación (Sánchez, 2014) e incluso al "mestizaje", a pesar de las connotaciones políticas del término, que revela un ejercicio explícito de dominio, violencia y sumisión.

Por otro lado, encontramos un conjunto de creadores que, acogidos al paradigma de la modernidad, buscan re-teatralizar la escena y el propio teatro ("reconstruirlo", dirá Meyerhold) ${ }^{3}$, lo que equivale a explorar y explotar la teatralidad y sus formas. Con este movimiento, nos llegan algunas de las más poderosas luminarias del teatro en el siglo XX. De Piscator a Grotowski, de Littlewood a Mnouchkine, de Brook a Barba, quienes mostrarán las posibilidades que ofrece una exploración rigurosa del concepto de teatralidad, la cual todavía mantiene su pulso en tantos escenarios del mundo.

Entre ellos, se encuentra Meyerhold, quien inicia su andadura teatral en Moscú. Primero, como alumno de arte dramático y discípulo de Nemiróvich-Dánchenko, después, como actor y colaborador con Stanislavski, en el Teatro de Arte de Moscú (TAM). Tras su salida definitiva del TAM, Meyerhold continúa una trayectoria marcada por la búsqueda de nuevas formas de hacer en la escena, de crear en el teatro, las cuales implicaban superar el ilusionismo escénico y ahondar en un nuevo paradigma. Él mismo lo define como "teatro de la convención consciente", el cual le lleva por los senderos de un constructivismo social que tiene en Lev Vygotsky uno de sus más sólidos promotores, en textos todavía fundamentales, como Psicología del Arte (2006).

2 Poco después de enviar este trabajo a Escena. Revista de las artes, en abril de 2019 falleció en Madrid Juan Antonio Hormigón, quien tanto trabajó en la divulgación de Meyerhold en España, editando varias de sus obras más importantes. Sirva la presente nota como muestra de reconocimiento y agradecimiento por su defensa permanente del legado del gran maestro ruso y soviético.

3 En 1930 pronuncia tres conferencias sobre el tema "La reconstrucción del teatro", en las que recupera muchas de las ideas formuladas en escritos anteriores (Meyerhold, 1971, pp. 240-251).

ESCENA. Revista de las artes, 2020, Vol. 80, Núm. 1 (julio-diciembre), pp. 69-95 
Todo ello, implicaba superar el viejo paradigma interpretativo asentado en métodos inductivos y desarrollar un nuevo paradigma basado en métodos deductivos. Como consecuencia, abandonó una construcción del personaje que partía de la psicología en favor de otras herramientas como la biomecánica, la comedia del arte, el juego dramático, o las formas del teatro popular u oriental (Tian, 2012), poco vinculadas a una ilusión escénica asentada en la verosimilitud. Meyerhold lanza sus propuestas, escénicas y teóricas, en un momento en el que, en Rusia, se desarrolla un importante movimiento de renovación en diversos ámbitos, como en el estudio de la lengua, la cultura y la literatura. Justamente, lo que hoy conocemos como Formalismo ruso, grupo muy diverso de investigadores y creadores quienes formulan teorías, construyen conceptos, proponen miradas que serán apropiadas desde otros campos y disciplinas, incluso desde el mundo del teatro. Así, nos llega la idea de Verfremdungseffekt o efecto de extrañamiento, que propondrá Brecht. El mismo que tiene sus orígenes en el concepto de ostranenie, elaborado por Eikhenbaum y Shklovski cuando explican la obra de arte como un artificio formal, la cual cabe reconstruir y deconstruir a partir de los elementos que la configuran. Esta es la idea que explora Meyerhold en sus espectáculos.

De sus propuestas consideramos las relativas al estudio de la comunicación artística, las cuales Meyerhold formula antes de 1913 y desarrolla posteriormente; incluso, antes de que se conozcan estudios de autores tan destacados como Jakobson (Vieites, 2016). En su estudio sobre la comunicación teatral, el espectador cobra relevancia, en lo que Fischer-Lichte define como su "descubrimiento" (1997, p. 41), y con él la recepción. Por lo tanto, se le debe considerar un precursor de las teorías de la recepción, fundamentales en la creación escénica, como señalará el dramaturgo y director de escena Sanchis Sinisterra (1995), en su propuesta de una "dramaturgia de la recepción". Dedicamos las páginas que siguen a confirmar ese aserto, pero, también, a considerar la importancia de su legado y de sus propuestas en el momento actual.

\section{Des-teatralizar, re-teatralizar y teatralidad}

Como se mencionó, entre finales del siglo XIX e inicios del XX, se generó en Europa un movimiento, diverso y disperso, que proclamaba, con mayor o menor énfasis, la urgencia de (re)teatralizar el teatro. Esto venía a significar el deseo de un teatro más asentado en su dimensión escénica frente a la literaria. Al mismo tiempo, se produjo una fuerte contestación del naturalismo, al entender que la reproducción exacta de la realidad limitaba las posibilidades del medio escénico, para desarrollar sus propias normas y códigos de composición, su gramática.

Así, a principios del siglo XX, Fuchs publica dos tratados, La escena del futuro (1904) y La revolución del teatro (1909), en los que plantea esa necesidad de re-teatralizar el arte 
teatral, presentado como "un renacimiento de la buena tradición" (1992, p. 209). Fuchs destacaba ideas que formaban parte de la revolución simbolista como la estilización y el abandono de lo real. Pero, introducía elementos nuevos, como la defensa del ritual y de la cultura popular (Perone, 2015), que serán asumidos por otros creadores. Así, desarrolló parte de su trabajo escénico en el Künstlertheater de Múnich, aunque sus ideas tendrán una amplia acogida en toda Europa. Si bien los resultados prácticos de sus indagaciones no parecieron ser del agrado de una parte de la crítica. Worringer dirá que más que re-teatralizar lo que hacía era des-teatralizar (Jelavich, 1985, p. 208).

Frente a esa tendencia, estudiada por Goldberg (1988), se sitúa aquella que desea explorar nuevas formas de "teatralidad", en tanto combinación de elementos de significación, frente a conceptos próximos como "dramaticidad", cualidad del texto, o la "escenalidad", tan explorada desde las artes de la acción. Uno de los creadores que más influencia tendrá en el movimiento de re-teatralización será Meyerhold, quien elaboró propuestas especialmente relevantes en el desarrollo del teatro en todo el siglo XX. Sus teorías más innovadoras en el campo de la interpretación y de la escenificación se exploran en espectáculos como Misterio bufo, a partir de un texto homónimo de Mayakovski o El cornudo magnífico, desde la obra dramática de Crommelynck. Su trabajo lo desenvolvió al mostrar, siempre, el funcionamiento de la fábrica escénica, en su convención, para destacar el hecho de que el teatro es una construcción artificial en la que actores, actrices y espectadores desarrollan sentidos de forma simultánea durante ese momento, central, en el que platea y escena se confrontan. Como señalan Arlander, Gröndahl y Silde (2016), "Meyerhold's audiences were constantly reminded that they were in a theatre, the quality of theatricality estranged by foregrounding its very texture [al público de Meyerhold se le advertía, de forma permanente, que estaba en un teatro, tornando como extrañas las formas de la teatralidad al situar, en primer plano, su textura real]" (p. 70). Así, utilizaba recursos que implicaban: "the curtain and the footlights might be abolished, the house lights left on, scenes shifted by stage-hands before their eyes [prescindir del telón y de las candilejas, dejar encendidas las luces de la sala, o realizar los cambios de escenario ante sus ojos]" (p. 70).

\section{Meyerhold}

Nuestro director se incorpora a la escena rusa en 1898, en el Teatro de Arte de Moscú (TAM), al finalizar sus estudios de interpretación en la Sociedad Filarmónica de Moscú, durante el año de su fundación. Allí, encarnó personajes de diversa relevancia. En 1902, inicia una nueva aventura, con Kosheverov, en la ciudad ucraniana de Kherson y en la georgiana de Tiflis. Inicia su trabajo como director de escena, aunque sigue la pauta naturalista de su maestro, Stanislavski. Será con esa compañía, la Sociedad del Nuevo Drama (SND), con la que empiece a formular la idea de un "nuevo teatro", con escenificaciones de autores simbolistas, como Maeterlinck, y el apoyo de críticos como Remizov (Abensour, 1998). 
Poco después volverá al TAM, aunque por poco tiempo. Cuenta Stanislavski, en Mi vida en el arte (2013), que algunas dificultades en la interpretación y la escenificación de textos de Maeterlinck le provocaron un "período de dudas y búsqueda" (p. 401). Entonces, aparece el viejo discípulo de quien dice el maestro:

Al cuarto año de existencia de nuestra compañía, se fue a provincias, reunió una compañía y emprendió la búsqueda de un arte nuevo, más moderno. Entre nosotros existía una diferencia: yo solo buscaba lo nuevo, sin conocer el camino ni los medios para alcanzarlo, mientras que Meyerhold, al parecer, ya había encontrado el camino, pero aún no estaba en condiciones de recorrerlo por completo, en parte por falta de medios materiales y en parte por la débil constitución de su elenco. Así que ya había encontrado a quien tanto necesitaba entonces en mis búsquedas. Decidí ayudarle en sus nuevos trabajos, que, según me pareció, coincidían en mucho con mis ideas. (p. 401)

En otoño de 1905, aquel primer estudio cierra sus puertas, debido a causas diversas, entre ellas, la Revolución de 1905, el cierre de los teatros y las dudas de Stanislavski en relación con el desempeño de actores y actrices. Sin embargo, tras el cierre, llegó la invitación de Vera Komissarzhevskaya, desde San Petersburgo, y la posibilidad de iniciar una etapa de experimentación, lejos del naturalismo y con la exploración de un simbolismo al que incorporó elementos de formas populares como la comedia del arte. Síntesis que llegaría con la escenificación de un texto de Blok, Balagancik (1906). Si bien, la colaboración con Komissarzhevskaya fue breve, con ella desarrolla experimentos fundamentales vinculados al trabajo del actor y a la plástica escénica. Así, crearon en la práctica un laboratorio de pruebas, causa primera y última de su despido.

Por ello, cuando en 1908 es contratado para dirigir en dos teatros de San Petersburgo, el Alexandrinsky y el Marinsky, traslada sus experimentos lejos del teatro imperial, con el que dirigirá espectáculos como Tristán e Isolda (1909), Don Juan (1910), Boris Godunov (1911), Orfeo y Eurídice (1911), La tempestad (1916), o Mascarada (1917). Estos montajes contaron siempre con la ayuda inestimable de Golovin, un escenógrafo que había colaborado con Diaghilev y sus Ballets Rusos en 1908 y 1910 (Abensour, 1998). En paralelo a esa actividad, participaba en iniciativas locales orientadas al desarrollo de formas escénicas nuevas, vinculadas con la dramaturgia popular o con su pasión por el teatro oriental. También, impartía clases de teatro (Leach, 2004, pp. 58-59) y para 1910 pone en marcha La Casa de los Interludios, en un antiguo teatro, el Sakzka, con la idea de presentar espectáculos de cabaret, pero, también farsas, pantomimas, operetas y otros géneros populares vinculados con lo burlesco y lo grotesco. Ideas y trabajos en línea con la experiencia que desarrollaba Nikita Baliev en Moscú, desde El Murciélago, un proyecto en el que colaboran artistas como Soudeikine (Segel, 1987). Meyerhold toma el nombre de Doctor Dapertutto, con el que anima proyectos variopintos en 
salas de vida efímera, que le permiten proseguir sus investigaciones, muy especialmente en la interpretación. Pero, también se adentra en las técnicas de escenificación, como ocurre en La desconocida (1914), sobre un texto de Blok, con el que explora climas sonoros para generar la atmósfera de una taberna (Braun, 1969, p. 116). Como dirá Styan (1981): "one key to understanding a Meyerhold production lay in his attitude to his audience [una clave para entender un espectáculo de Meyerhold residía en su actitud hacia la audiencia]" (p. 77).

Un hecho fundamental en su trayectoria será la puesta en marcha, en San Petersburgo, durante el otoño de 1913, de una escuela teatral que funcionará como estudio de formación y laboratorio de investigación. En ese mismo año, publica un tratado teórico, Del teatro, que contiene artículos especialmente relevantes, los cuales definen, con precisión, aspectos básicos de su poética, desde la idea de "convencionalidad" a la importancia de la formación de un actor pensante:

Walter Benjamin, one of Brecht's closest friends as well as one of his earlier explicators, noted that Meyerhold's actors were unique because they could simultaneously perform and think. From the thinking actor to the thinking spectator is a short but crucial step which completes the circle of mutual interaction and creativity. If Meyerhold often seemed "intellectual" for his audiences, it was because he expected from them a creative effort to match his own [Walter Benjamin, uno de los más íntimos amigos de Brecht y uno de sus más tempranos exégetas, señaló que los actores de Meyerhold eran únicos porque podían representar y pensar al mismo tiempo. Del actor pensante al espectador pensante hay un paso, breve pero crucial, que completa el círculo de la interacción y la creatividad mutuas. Si Meyerhold a veces resultaba "intelectual" a sus públicos, era porque de ellos esperaba un esfuerzo creativo similar al suyo propio]. (Eaton, 1985, p. 2)

Con la Revolución de Octubre, Meyerhold asume un rol relevante en la organización teatral del nuevo país que se construye, tanto en lo que atañe a la creación como a la formación. Organiza actividades de cualificación escénica politécnica, como el "Curso de introducción a la escenificación" que dicta en Petrogrado, en junio de 1918 (Meyerhold, 2010)4. En este año presenta Misterio Bufo, sobre un texto de Mayakovski, con la colaboración de Malevich. Un año después Les Aubes, con un texto de Verhaeren. Poco después, entre 1921 y 1922 desarrolla los aspectos sustantivos de su biomecánica y, a la vez, irrumpe el constructivismo teatral con El cornudo magnífico (1922), que presenta al amparo de la Oficina Estatal Superior de Teatro, un centro de formación bajo su supervisión (Javier, 2009).

${ }^{4}$ El curso y otros materiales complementarios se recogen en un volumen fundamental en la comprensión de sus teorías escénicas, titulado Lecciones de dirección escénica, editado en castellano por el profesor Jorge Saura (Meyerhold, 2010).

ESCENA. Revista de las artes, 2020, Vol. 80, Núm. 1 (julio-diciembre), pp. 69-95 
Podría decirse que, en todo ese proceso creativo, que se prolonga hasta 1935, Meyerhold transita por varias fases: el naturalismo de sus primeros trabajos; el simbolismo en su etapa de San Petersburgo; la farsa grotesca y popular en sus estudios y, en la misma ciudad, la agitación y la propaganda del Octubre Teatral (Misterio bufo); el constructivismo (El cornudo magnífico), e incluso, la factografía, con proyectos como El mandato. En todas ellas, desde su reivindicación de un nuevo teatro, que se habría de generar a partir de la recuperación de tradiciones teatrales perdidas, asoma la idea de una "convencionalidad" asentada en un creciente anti-ilusionismo. Una formulación teórica derivada de la praxis que afectaba a la dramaturgia, la interpretación o el diseño escénico en su conjunto. Así, desmontaba los procedimientos habituales de la recepción, "extrañando" el visionado, en línea con lo que proponían formalistas rusos como Eikhenbaum o Shklovski. Emerge una visión nueva, no solo del espectáculo sino también del espectador, pues lo que se está gestando en toda la experimentación que desarrollan directores como Meyerhold, Eisenstein o Vajtangov es un modelo nuevo de creación teatral.

\section{Un nuevo paradigma}

En esta propuesta partimos de la lectura que en 1965 propuso Habermas (1986) en torno a los usos del conocimiento y a los paradigmas derivados de estos. Pero, también a partir de la visión que sobre el concepto nos traslada Kuhn (1975) al señalar que:

los cambios de paradigma hacen que los científicos vean el mundo de investigación, que les es propio, de manera diferente. En la medida en que su único acceso para ese mundo se lleva a cabo a través de lo que ven y hacen, podemos desear decir que, después de una revolución, los científicos responden a un mundo diferente. (p. 176)

Como decíamos en otro lugar (Vieites, 2008), los artistas contribuyen a generar tales revoluciones movidos por dinámicas sociales instaladas en formas de ver y querer el mundo, en estructuras de poder, discursos y artefactos culturales, en ningún caso ajenos a las ideologías. Por eso, relacionando conocimiento, interés y finalidad, Habermas (1984) consideraba la existencia de tres grandes paradigmas científicos:

En el ejercicio de las ciencias empírico-analíticas interviene un interés técnico del conocimiento; en el ejercicio de las ciencias histórico-hermenéuticas interviene un interés práctico del conocimiento, y en el ejercicio de las ciencias orientadas hacia la crítica interviene aquel interés emancipatorio del conocimiento que ya, como vimos, subyacía inconfesadamente en la ontología tradicional. (p. 168)

Queda fuera de foco la visión de la ciencia que pueda derivar de la condición posmoderna, tan vinculada a la idea de fin y, por tanto, de la muerte, como bien explicaba Bunge (2002). Entendemos que el concepto de ciencia es ajeno a tal condición, pues el

ESCENA. Revista de las artes, 2020, Vol. 80, Núm. 1 (julio-diciembre), pp.69-95 
propio Lyotard habría considerado la paralogía como una substituta factible de la misma, al objeto de impregnar de heterogeneidad, eclecticismo, diversidad, horizontalidad, incluso debilidad, el mundo del pensamiento, pero, también, a la creación, como nos muestra el arte posmoderno, entre ellos, el teatral (Diéguez, 2006). Con todo, tras la efervescencia de la fiebre posmoderna, se han propuesto interesantes desarrollos de nuevas formas de entender la ciencia y de producir conocimiento. Así lo vemos en su gestión y en sus usos (Hessels \& van Lente, 2008; Jiménez-Buedo \& Ramos Vielba, 2009) con denominaciones como "ciencia postacadémica" o "ciencia postnormal" (Funtowicz \& Ravetz, 2000), que también implican formas nuevas de entender la creación artística, aunque todo ello requiera un análisis demorado.

Al considerar el desarrollo de los siglos XIX y XX, junto a tendencias consolidadas en el actual siglo XXI, podríamos señalar relaciones entre ciencias, sus finalidades, paradigmas estéticos, y estilos artísticos, como proponemos en la tabla 1:

Tabla 1. Paradigmas y estilos.

\begin{tabular}{|c|c|c|c|c|}
\hline & Ciencias & Finalidad & Paradigma & Estilos artísticos \\
\hline 1 & Empírico-analíticas & $\begin{array}{l}\text { Describir } \\
\text { Explicar }\end{array}$ & $\begin{array}{l}\text { Mimético } \\
\text { Ilusionista }\end{array}$ & $\begin{array}{l}\text { Noclasicismo } \\
\text { Naturalismo } \\
\text { Costumbrismo } \\
\text { Realismo } \\
\text { Hiperrealismo }\end{array}$ \\
\hline 2 & Histórico-hermenéuticas & $\begin{array}{l}\text { Comprender } \\
\text { Interpretar }\end{array}$ & $\begin{array}{l}\text { No mimético } \\
\text { No ilusionista }\end{array}$ & $\begin{array}{l}\text { Romanticismo } \\
\text { Simbolismo } \\
\text { Expresionismo } \\
\text { Surrealismo } \\
\text { Absurdo }\end{array}$ \\
\hline 3 & Socio-críticas & $\begin{array}{l}\text { Revelar } \\
\text { Transformar } \\
\text { Emancipar }\end{array}$ & $\begin{array}{l}\text { Anti-mimético } \\
\text { Anti-ilusionista }\end{array}$ & $\begin{array}{l}\text { Futurismo ruso } \\
\text { Constructivismo } \\
\text { Nueva objetividad } \\
\text { Épico } \\
\text { Documentalismo }\end{array}$ \\
\hline 4 & $\begin{array}{l}\text { Pos-normales } \\
\text { Pos-académicas }\end{array}$ & $\begin{array}{l}\text { Mostrar } \\
\text { Presentar } \\
\text { Narrar }\end{array}$ & $\begin{array}{l}\text { Paralógico } \\
\text { Fractal } \\
\text { Rizomático }\end{array}$ & $\begin{array}{l}\text { Futurismo italiano } \\
\text { Dadaísmo } \\
\text { Cubismo } \\
\text { Conceptualismo } \\
\text { Live/action art }\end{array}$ \\
\hline
\end{tabular}

Fuente: Elaboración propia.

ESCENA. Revista de las artes, 2020, Vol. 80, Núm. 1 (julio-diciembre), pp. 69-95 
Conviene no perder de vista el hecho de que una parte de los artistas quienes asoman al Octubre Teatral tienen muy presente su rol como científicos sociales y culturales, como productores, ya sea ingenieros u obreros. Desde esa posición, especialmente los constructivistas proponen una visión nueva de la obra de arte y de sus funciones, al tiempo del propio artista (De Micheli, 2002). Ese tránsito es particularmente relevante en Meyerhold, quien se abona al primer paradigma en sus primeros trabajos, fundamentalmente, como actor. Confirma su trayectoria como director de escena en el segundo, con su deriva simbolista y se instala, definitivamente, en el tercero con su obra de madurez, siendo, en esa dirección, un antecesor de Brecht. Sobretodo, cuando consideramos que ya en aquellos primeros espectáculos que dirige en San Petersburgo, como Balagancik, asoma el concepto de ostranenie, es decir, la idea de que el arte, como escribiera Shklovski, es un artificio, o como entendía Eikhenbaum "un medio de destruir el automatismo perceptivo" (2005, p. 61). Cuando Shklovski señalaba que "los procedimientos del arte son el del extrañamiento del objeto" y que buscan "aumentar la dificultad y la duración de la percepción" (2005, p. 73), estaba, en buena medida, haciendo entrar en juego al lector y, en nuestro caso, al espectador.

\section{La escuela de la recepción}

En 1967, Hans Robert Jauss, también incluirá al lector, en una conferencia pronunciada en la Universidad de Constanza, bajo el título de La historia de la literatura como provocación a la ciencia literaria, publicada ese mismo año. Se trata de uno de los textos inaugurales de lo que se conoce como estética de la recepción (Mayoral, 1987; Warning et al., 1989), que se vincula con la hermenéutica literaria (Domínguez, 1997). Pero, también relacionada con la obra de notables pioneros como Román Ingarden (1989) o incluso Hans-Georg Gadamer, como señala Emilio Lledó (1985). La estética de la recepción vendrá a señalar la importancia del lector, pues como escribe Wolfgang Iser, allí "donde el texto y el lector convergen, ese es el lugar de la obra literaria" (1987, p. 44). Otros profesores, en otros países, como Stanley Fish, Umberto Eco, Hayden White, Vítor Manuel de Aguiar e Silva, Siegfried J. Schmidt, o Fernando Lázaro Carreter han realizado, igualmente, notables contribuciones al destacar la dimensión comunicativa de la literatura, en la que el lector juega un rol importante. A tal punto que Teun A. Van Dijk plantea una "pragmática" de la comunicación literaria (Mayoral, 1999; Cuesta \& Jiménez, 2005). Así, de igual modo, se debiera formular una pragmática de la comunicación teatral.

Más allá de los desarrollos que tal teoría haya tenido en el estudio de la recepción teatral ${ }^{5}$ interesa, muy especialmente a los objetivos del presente trabajo, la lectura que pro-

\footnotetext{
${ }^{5}$ Ver Iglesias, (1994); Bennett, (1997).
} 
pone Sanchis Sinisterra (1995). En su ideación de una "dramaturgia de la recepción" plantea cuestiones sustantivas en relación con el rol del espectador como "creador" del espectáculo teatral. Pero, también, aborda el concepto de teatralidad (Sauter, 2000), que nos devuelve a la cuestión de los paradigmas, en tanto cada uno propone su propia teatralidad; si bien en el cuarto de los antes señalados debiéramos hablar más bien de "escenalidad". Entonces, ¿cuáles son las ideas fundamentales que nos trasladan? En primer lugar, la producción del significado, que no está dado de antemano, sino que se construye en la recepción, a través de la actividad del receptor. Una idea que implica, además, que la obra está abierta, lo que nos lleva a la idea de "indeterminación", que Ingarden (1989) señala como una característica fundamental de toda obra de arte:

La presencia de lugares de indeterminación no es algo accidental, el resultado de un defecto de composición. Más bien es necesaria en toda obra literaria de arte. Es imposible establecer con claridad y exhaustividad la multiplicidad infinita de determinaciones de los objetos individuales representados en la obra, con un número finito de palabras o frases. Siempre tendrá que faltar alguna determinación. (p. 37)

En segundo lugar, la importancia del receptor y de la idea de un receptor implícito. Cuestión que, como señala Braun (1986) ya había sido propuesta por Fuchs (1959), quien ya en 1909 escribía que "it is in the spectator that the dramatic work of art is actually born -born at the time it is experienced-, and it is differently experienced by every individual member of the audience [es en el espectador donde nace, en realidad, la obra de arte dramática y nace en el momento en que se percibe, siendo percibida de forma diferente por cada una de las personas que integran el público]" (p. 43). En todas las reflexiones de Meyerhold, en torno a la escenificación, hay una referencia constante al espectador y a su rol activo. Así, escribe: "el realizador que monta su espectáculo sin tener en cuanta al público comete un craso error: cuando el espectáculo aún no ha sido estrenado, es muy difícil saber cómo reaccionará el público" (1972, p. 255).

En tercer lugar, interesa la importancia del proceso de comunicación. Antes de que Jakobson formulase sus propuestas, en torno a la comunicación literaria (1975), e incluso antes de que Lasswell, o Shannon y Weaver, propusiesen sus modelos sobre la comunicación (Martín, 2004), Meyerhold establece un continuum que va del autor al espectador, con el director y el actor. En este, Meyerhold destaca un momento central, recuperado más tarde por Brook o Grotowski (Vieites, 2017), al decir, en torno a 1907, que "del encuentro de estos dos elementos libres -la creación del actor, y la fantasía creadora del espectador- se enciende la verdadera llama del arte" (1971, p. 161). En 1927, insistirá en la misma idea, pues "el espectáculo, claro está, es una labor conjunta del actor y del espectador" (1972, p. 250). 
Como cuarta idea relevante, se encuentra la defensa radical del espectador, pues, en su crítica al teatro naturalista escribirá, ya en 1906, que: "el teatro naturalista niega al espectador no solo la capacidad de soñar, sino también la de comprender los discursos inteligibles sobre la escena" (Meyerhold, 1971, p. 133).

Finalmente, interesa el horizonte de expectativas, concepto analizado extensamente por Iglesias Santos (1994), el cual nos viene a decir que todo espectáculo construye su receptor implícito, que no siempre coincide con su receptor histórico. Un problema explorado por Meyerhold en algunos de sus primeros espectáculos, que estaban fuera de toda sintonía con su público potencial y real. Como señala Pitches (2003), en espectáculos como Balagancik, de 1906, se proponían "sharp changes in atmosphere and collisions of ideas and of styles, all of which were designed to keep the audience alert and responsive [cambios bruscos en la atmósfera y colisiones de ideas y estilos, todos concebidos para mantener al publico alerta y reactivo]" (p. 19). En relación con el proyecto La muerte de Tintagiles, de 1905, Pitches (2003) escribe:

The essence of Meyerhold's symbolist approach is therefore made clear: to enhance the imaginative input of the spectator by making strange the actor's body and voice and placing them in a darkened, non-specific theatrical environment. Plasticity (the movements of the actor) works alongside musicality (in the voices of the actors and in the composer's score) to create a sometimes harmonious, sometimes dissonant theatrical effect [La esencia del enfoque simbolista de Meyerhold se hace entonces patente: potenciar la contribución imaginativa del espectador haciendo que resulten extraños el cuerpo y la voz del actor y situando a este en un entorno teatral oscurecido, inconcreto. La plasticidad (los movimientos del actor) se combina con la musicalidad (en las voces de los actores y en la partitura del compositor) para crear un efecto teatral unas veces armonioso y otras disonante]. (p. 11)

En esa defensa de un nuevo modelo de comunicación teatral, en la que fustiga al teatro naturalista por no admitir "nunca una interpretación alusiva, una interpretación que deje conscientemente zonas de sombra en el personaje" (1971, p. 131), Meyerhold propone un nuevo teatro, con él y en él una nueva teatralidad.

Tampoco es este el espacio para una digresión sobre la idea de teatralidad, que no debe confundirse con un concepto próximo como "dramaticidad". El primero hace referencia a la forma en que se combinan los elementos de significación, pero, también a los modos en que se construye la ficción escénica y a los procesos de comunicación que esa ficción desarrolla (Vieites, 2016). Como señalaba Barthes, en 1963, la teatralidad cabe entenderla como un "espesor de signos", como una "polifonía informacional" (1973, p. 310), que se desata con la entrada del espectador al espacio teatral, pero, que ya puede iniciarse antes, cuando el espectáculo emerge en la esfera pública. 
La cuestión del espesor de signos, abordada por Kowzan en su trabajo seminal "El signo en el teatro" (1997) y, posteriormente, en numerosos estudios de semiótica y semiología teatral (Aston \& Savona, 1991; Elam, 2002), relacionados con la gramática del espectáculo (en su morfología, en su sintaxis, y en su semántica), debe complementarse con la dimensión pragmática. Esto al abordar cuestiones fundamentales en relación con el espectador, quien siempre configura todo espectáculo, sea como receptor ideal o como receptor real. Es justo aquí donde emerge la figura de Meyerhold como uno de los grandes pioneros, tanto en la configuración de una nueva teatralidad como en el desarrollo de un nuevo paradigma escénico asentado en ella. Todo ello sin olvidar el hecho de que sea el primero en desarrollar un paradigma de signo deductivo en teoría de la interpretación, como alterativa al paradigma inductivo propuesto por su maestro Stanislavski, cuestión que abordaremos en otro trabajo.

\section{Constructivismo(s) y recepción}

En la documentada panorámica que analiza su obra, Hormigón (1971) indica que, en sus primeros trabajos, Meyerhold enfrenta dos "problemas capitales", los cuales atañían al actor y al director de escena, como eran "la dicción y la plástica" (p. 40). Ello sin olvidar el movimiento, la dimensión física del actor o sus relaciones con el personaje, lo que implica al espectador, en tanto se rompen automatismos en la recepción. Así lo explicó Meyerhold durante 1912, en su revisión de Balagancik, lo que puede leerse como un anticipo claro del extrañamiento y del rol del actor, al decir que:

cuando el espectador es arrastrado por el actor demasiado adentro en el país de invención, el actor inmediatamente le recuerda, con una réplica repentina o con una larga parrafada, que todo lo que sucede ante sus ojos es "pura interpretación". (1972, p. 37)

Así, nace el "teatro de la convención consciente" que no solo se debe entender como superación del naturalismo, sino, también, del simbolismo, camino del constructivismo. Asimismo se inicia una escena que se declara anti-mimética, en su deseo por descubrir y hacer patentes los mecanismos de la convención, la artificialidad del producto escénico, la fábrica teatral y para potenciar su operatividad a la hora de desvelar la realidad. Esta es una tarea conjunta en la que participan actores, actrices y público. Si Barris (2013) señala que "the constructivist contribution to theatre has rarely been conceptualized in terms of the creation of a new relationship among the theatrical object, the actors, and the audience [la contribución constructivista al teatro muy pocas veces se ha analizado en función de la creación de una nueva relación entre el objeto teatral, los actores y el público]" (2013, p. 57), Pitches, por su parte, nos recuerda que "Meyerhold delighted in revealing the mechanics of the theatre. He filled his productions with self-conscious theatricalities, arranging the order of the scenes in such a way that they might collide against one another rather than seamlessly 
fuse together [a Meyerhold le encantaba mostrar la mecánica teatral. Llenaba sus espectáculos con teatralidades autoconscientes, organizando el orden de las escenas de tal modo que pudiesen colidir entre sí en lugar de buscar una unión perfecta entre ellas]" (2003, p. 3).

Este es un procedimiento que renuncia al ilusionismo, lo revela y lo desvela, mediante el cual se quiere mostrar la convencionalidad, la artificialidad del teatro y su carácter de proceso en construcción. Aflora, con fuerza, el constructivismo, movimiento heterogéneo, sumamente diverso, que puede considerarse desde muy diversas perspectivas, desde la epistemológica hasta la propia de diferentes ciencias, con la sociología o la pedagogía. Como señalaba López: "hay una gran diversidad en las distintas invocaciones al constructivismo, pero en todas ellas hay un sustrato invisible, un hilo de continuidad" (2010, p. 27). Ese sustrato invisible, esa identidad compartida deriva del hecho de que: "el aspecto central del constructivismo está dado por su interés en reconocer el fenómeno del conocimiento como resultado de una interdependencia entre observador y mundo observado" ( $p .28)$, lo que en teatro equivale a decir entre espectador y mundo escénico. Si, como señalaban Berger y Luckmann (1986) la realidad es una construcción social, con más razón lo será la obra de arte, un artefacto que se reconstruye por medio de la actividad del espectador.

Meyerhold es considerado el director teatral que traslada al campo de la escena los principios del constructivismo. Un movimiento muy heterogéneo que en Rusia y en la Unión Soviética deja sentir su impronta en el ámbito de la arquitectura, con Tatlin o Vesnin (Kirikov \& Vallye, 2008). Así como en el diseño gráfico con Popova, Stepanova o Rodchenko (Gan, 2014). En sus propuestas y en su visión del arte como actividad productiva, se percibe una voluntad doble, ya sea al mostrar la naturaleza de la obra de arte, en tanto construcción en su forma, estructura y elementos, como de implicar al receptor en su reconstrucción, en tanto productor. Pero, no se trata de una formulación que provenga en exclusiva del teatro, el diseño o la arquitectura. Uno de los más importantes psicólogos de aquel momento, llegará a conclusiones similares al desarrollar lo que se conoce en Ciencias de la Educación como "constructivismo social" (Blanck, 1990).

Hablamos de Vygotsky, autor de un libro fundamental en la comprensión de la comunicación artística y que nos sitúa ante otra cara del constructivismo. En el capítulo titulado "El arte como percepción", en Psicología del Arte, Vygotsky propone algunas ideas interesantes que habría gestado entre 1915 y 1922. Entre ellas, la que ahora nos ocupa. Como señala Leontiev en la introducción al volumen, Vygotsky, a partir de un método analítico y objetivo, entendía que: "al analizar la estructura de una obra de arte uno debe recrear la respuesta, la actividad interna a que dicha obra da pie” (2006, p. 15). O por citar la formulación del propio autor: 
Las palabras, por su misma naturaleza psicológica, casi siempre excluyen las imágenes gráficas. Cuando un poeta habla de un caballo, la palabra no implica crines al viento, galopes, entre otros. Todo significado adicional de este tipo es aportado (y por lo general de modo bastante arbitrario) por el lector. (Vygotsky, 2006, p. 71)

Esa mirada hacia la recepción, hacia el rol del lector o del espectador, ya había sido propuesta por un autor especialmente relevante, Christiansen. En su trabajo Philosophie der Kunst (1909), publicado en ruso en 1911, que, como señala Erlich: "fue uno de los pocos estudios de Europa occidental citado aprobatoriamente por los teóricos de Opojaz" (1974, p. 255). Además, en palabras de Radunovic fue objeto de una "prolific reception [recepción prolífica]" (2015, p. 6) entre los formalistas, especialmente, por la atención con que analiza los procesos de la percepción artística.

\section{El teatro de la convención consciente y el espectador}

La trayectoria escénica de Meyerhold ha sido sintetizada en trabajos diversos (Hormigón, 1971; Hoover, 1974; Leach, 1993; Abensour, 1998; Braun, 2006). En ellos se analiza el recorrido que inicia en el Teatro de Arte de Moscú (TAM) como actor y que, luego, continúa como director, especialmente, en San Petersburgo, para, finalmente, vincularse con la Revolución de Octubre y con el constructivismo. Además de espectáculos centrales en la renovación teatral del siglo XX, Meyerhold nos lega un conjunto muy diverso de escritos.

Tales textos, sean de carácter teórico o sean reflexiones de espectáculos concretos, cubren unos 30 años, al menos si consideramos títulos como "El teatro naturalista y el teatro de atmósfera" (1906) o "Meyerhold contra el meyerholdismo" (1936). Un período en el que se producen transformaciones importantes, entre ellas la conversión de Rusia en la Unión Soviética y el tránsito entre la fiebre vanguardista y el realismo socialista. En medio quedan los futurismos, los teatros de agitación y propaganda, el Octubre Teatral, los constructivismos, el productivismo o la factografía, como principales tendencias artísticas, que van a tener un peso considerable en las prácticas escénicas (Gray 1962; Markov 1968; Mally, 1990; Harrison \& Marquardt 1992; Gassner 1992; Zalambani 1998; Hormigón, 2017). No se debe olvidar que Meyerhold vive en primera persona todo ese proceso, al transitar por tales tendencias y por los paradigmas en que se ubican, del mimético al anti-ilusionista.

Precisamente, uno de los grandes desarrollos teóricos y prácticos del teatro ruso de finales del siglo XIX y principios del XX es el concepto de "cuarta pared", que emerge en espectáculos dirigidos por Stanislavski sobre textos de Chéjov (La Gaviota, 1898; Tío Vania, 1899; Las tres hermanas, 1901; El jardín de los cerezos, 1904). Este concepto implicaba una determinada actitud por parte del público, sobre la que Meyerhold dirá, ya en 1906: "el teatro naturalista, evidentemente, niega al espectador la capacidad de completar el cuadro 
y de soñar como cuando se escucha música” (1971, p. 132). Después, explicará: “¿Por qué el drama medieval podía prescindir de artificios escénicos? Gracias a la viva fantasía del espectador" (1971, p. 133).

Como señala Kleberg, el naturalismo excelso del TAM provocó una reacción contraria, asentada en la poética simbolista. En ella destaca la figura de Bryusov, quien defiende el teatro convencional frente al teatro realista o casi realista, al indicar que el primero confía en la imaginación del espectador, para crear el contexto en que situar la acción del actor (Senelick, 1981). Así, lo reconocerá Meyerhold hacia 1907 al señalarle como: "el primero en indicar nuevos caminos para la representación dramática, invitando a substituir la inútil verdad de las escenas modernas por una convencionalidad consciente" (1971, p. 143). También lo hará al reclamar con él que la escena debe ofrecer al espectador todo aquello que pueda ayudarle a "reconstruir fácilmente en su imaginación el ambiente requerido por la trama de la obra" (p. 145). En esa línea, Meyerhold apuesta por la estilización, principio que aplica a toda la escenificación, sea en el trabajo del actor, sea en la iluminación o el diseño escénico.

Durante su etapa más simbolista, en la que también inicia sus experimentos e investigaciones, continuación de las desarrolladas en el Primer Estudio del TAM, Meyerhold, de la mano del Doctor Dapertutto, va mucho más allá de lo que reclamaba la escenificación de los textos simbolistas de Maeterlinck, o de lo que proponía Bryusov. En un trabajo titulado "El grotesco como forma escénica", reivindica la figura de Wolzogen y con él toda una tradición en la que la escena se llenaba de espectáculos de variedades, cabaret, marionetas, o números de circo. Esto implicaba una estética popular, más próxima al teatro isabelino que al simbolismo. Por eso, siguiendo a Wolzogen en su defensa del grotesco, señala dos etapas necesarias en la renovación escénica. La primera, conduce a la estilización, en tanto: "the impossibility of embracing the totality of reality justifies the schematization of the real (in particular by means of stylization) [la imposibilidad de abarcar la realidad en su totalidad, justifica la esquematización de lo real (particularmente por medio de la estilización)]" (Meyerhold en Braun, 1969, p. 137). La segunda, decisiva, supone un cambio de paradigma:

Stylization impoverishes life to the extent that it reduces empirical abundance to typical unity. The grotesque does not recognize the purely debased or purely exalted. The grotesque mixes opposites, consciously creating harsh incongruity and relying solely on its own originality [La estilización empobrece la vida al punto de que reduce la abundancia empírica a lo que tenga de común. Lo grotesco no se ocupa únicamente de lo degradado o únicamente de lo exaltado. Lo grotesco mezcla opuestos, creando conscientemente una incongruencia estridente y confiando solo en su propia originalidad]. (Meyerhold en Braun, 1969, p. 138) 
Si bien el teatro simbolista no buscaba recrear la realidad en sus mínimos detalles, sino mostrar su esencia en un juego de sugerencias, en las que el símbolo adquiere relevancia y en una escena no-mimética, la propuesta de Meyerhold busca mostrar la artificialidad del teatro mostrando su fábrica. Una convencionalidad que tampoco se avenía con la defendida por Bryusov, pues dice Meyerhold, en 1907:

En el teatro "de la convención consciente" el espectador "no olvida ni por un instante que tiene ante sí un actor que representa, ni el actor que tiene ante él una sala, bajo los pies un escenario, y a los lados un decorado. Sucede lo mismo que con un cuadro: mirándolo uno no se olvida ni por un instante que se trata de colores, de tela y de pinceles..." (1971, p. 161)

Tal vez por ello, en relación con el espectáculo D. E. (1924), comenta Meyerhold, en 1926, sobre el principio de la transformación (varios papeles encomendados a un actor):

Por regla general, el realizador que recurre a la transformación para disminuir el número de intérpretes, oculta al público el hecho de la transformación. Nosotros, por el contrario, lo anunciamos en los carteles e invitamos al público a que observe con que arte el actor se transforma. (1972, p. 79)

Esa ruptura de la cuarta pared, de la ilusión, del misterio, implica un nuevo modelo de escenificación y un actor nuevo, aquel que emergerá en los nuevos espectáculos tras la Revolución de Octubre. Pero, que ya prefigura en este comentario:

En un día otoñal, lluvioso, por la calle se alarga un cortejo fúnebre. Por la actitud que adoptan las gentes que marchan tras el féretro, se ve una profunda condolencia; de repente, el viento arranca el sombrero de la cabeza de uno de los apenados acompañantes. Se inclina a recogerlo, pero el viento se lo lleva de una parte a otra. Cada salto del compungido señor tras el sombrero obliga a su cuerpo a contorsiones tan cómicas que una mano diabólica transforma de repente el tétrico cortejo fúnebre en multitud festiva. ¡Ojalá pudiésemos lograr ese efecto sobre el escenario! (Meyerhold, 1971, pp. 180-181)

Ese teatro llegó tras su último trabajo en San Petersburgo (Mascarada, 1917). Aunque este ya asomaba en algunas propuestas de su escuela-estudio, acompañado de la biomecánica, el constructivismo y el productivismo del espectador.

Al formular la idea del teatro como "convención consciente", señala que todas las personas participantes en el acto teatral asumen que lo ocurrido en la escena es una ficción. Esto afecta el trabajo del director, del actor y del espectador, pues todos son conscientes de estar construyendo, de forma consciente, una convención. Meyerhold lo explica de nuevo, en 1933, al decir que "el escenario está hecho de manera que no puede contener la vida. 
Decimos que no es esta la tarea del arte. El teatro es convencional por su misma naturaleza" (1971, p. 260), razón por la que se declara en contra de "producir la ilusión de realidad" (p. 260). A la vez, anuncia que: "ya es hora de acabar con la ilusión de la realidad" (p. 260). Dicho con otras palabras, "el teatro se ha convertido en presa de la carpintería" (1971, p. 137). Esta afirmación de 1906, supone una declaración de principios, camino de un espacio escénico, en el que mostrar la convencionalidad de la puesta en escena. De la negación del ilusionismo pasamos al anti-ilusionismo.

En efecto, en trabajos muy anteriores a 1933, como "Los primeros intentos del teatro 'de la convención'” o “El teatro 'de la convención'” Meyerhold (1971) formula ya los principios de esa estética, que camina entonces entre el no-ilusionismo y el anti-ilusionismo. Pero, también establece otra de las ideas que queremos destacar:

El método "convencional", finalmente, presupone en el teatro un cuarto creador, después del autor, el director y el actor: el espectador. El teatro "de la convención" crea una puesta en escena cuyas alusiones debe completar el espectador creadoramente, con su propia imaginación. (p. 161)

Años después, en 1930, en el trabajo titulado "La reconstrucción del teatro" señala que: "el dramaturgo y el director de escena no elaboran más que un armazón", y deben concebirlo en su opinión "de una manera lo bastante amplia para dejar lugar común al trabajo común de los actores y de los espectadores" (1971, p. 214). En otro trabajo, especialmente relevante, de 1933, dirá:

El espectador que viene al teatro sabe que no se pretende una copia de la realidad, sino que él mismo debe, durante todo el tiempo del espectáculo, tratar de reconstruir el mundo con ayuda de su propia capacidad asociativa, partiendo del boceto que se le ofrece desde la escena. En vez de una casa completa verá un trozo de estufa o una ventana. (1917, p. 261)

Desde sus primeros trabajos Meyerhold concede al espectador un rol fundamental en el proceso de creación y recepción, al señalarlo como cuarto creador (1971, p. 148). Incluso, mucho antes de que se formulasen teorías productivistas relativas al arte. Por otro lado, no debemos dejar de señalar que, con su llegada a lo que se denominará Teatro número 1 de la República Socialista Federativa de los Soviets de Rusia (RSFSR), se ponen en marcha algunas experiencias interesantes en el campo de la sociología del teatro, referidas a estudios de la recepción. Abensour incluye en su magnífico tratado un formulario distribuido en las funciones de los primeros espectáculos de la compañía, que resulta ciertamente interesante (1998, p. 519). Kleberg explica cómo el uso de cuestionarios comenzó en torno a 1917, con Alexander Bardovsky y otros directores y destacaba la importancia del público en aquellos primeros años. Además, señala que: "this almost phenomenological approach to the theatre perfor- 
mance as an object, concretised in the interplay between the actively perceiving spectator and the stage, seems very far ahead of time [este enfoque casi fenomenológico de la representación teatral como objeto, que se concreta en la interacción entre un espectador activo en su percepción y la escena, parece muy avanzado en su época]” (Kleberg, 1993, p. 96.)

\section{A modo de conclusión}

Meyerhold, con sus experiencias teatrales, propone un nuevo paradigma escénico, que toma cuerpo en su etapa constructivista, aunque ya asome en propuestas anteriores. En ese modelo destaca la importancia del receptor como sujeto creador del espectáculo. Al dejar atrás el simbolismo inicial, Meyerhold reconstruye la escena a partir del concepto de "convencionalidad", mostrando, en todo momento, la fábrica del teatro, con ella y en ella la dimensión productiva de la recepción.

El nuevo paradigma supone otra forma de entender la teatralidad, más orientada a mostrar el artificio del espectáculo. Con ello, cobran importancia los elementos diversos de significación que, hasta ese momento, eran secundarios o prescindibles, debido a la supremacía del texto y del hiperrealismo. En ese nuevo paradigma también cobra especial relevancia la idea de montaje (Mueller, 1987). Esto implica una estructura episódica no causal, que busca, entre otras cosas, la activación del espectador como sujeto de la recepción, o como señala Pitches (2003), "a thinking audience, putting together the meaning by itself [un público pensante, que creaba el significado por sí mismo]" (2003, p. 75), lo que también implicaba su formación (Scheinin, 2009, p. 45).

El abandono del psicologismo en la construcción del personaje también será fundamental en el desarrollo de ese nuevo paradigma. En un escrito de 1925, "Juego y prejuego", Meyerhold (1971) propone abandonar el psicologismo inductivo de Stanislavski. Ya mucho más cerca del pensamiento hipotético-deductivo, señala:

si tenemos que representar un espectáculo triste, es inútil que tratemos de hacer como hizo durante un tiempo el Teatro de Arte y nos pongamos a vagabundear por callejones oscuros, acumulando y concentrando en nosotros los correspondientes estados de ánimo. Nosotros decimos simplemente: por favor, no penséis en ello, no os preocupéis, os daremos una puesta en escena que os sugerirá los estados de ánimo correspondientes a las situaciones físicas en que os pondremos (p. 267).

Con ello, Meyerhold establece principios básicos de lo que serán propuestas de Brecht, cuando aquel dice, en 1925, que su "actor tribuno" "se plantea la obligación de desarrollar su acción escénica no en la dirección en que las situaciones escénicas son "bellas" por su teatralidad. Más bien, en aquella otra donde él, el actor, como un ciru- 
jano, desvela el interior (de la situación escénica)" (1972, p. 116). Eso implica, en sus palabras, que "el actor-tribuno descubre a los ojos del público la verdadera naturaleza de un personaje bajo la capa (el velo) del personaje" (p. 116).

Tal como lo mencionó Meyerhold (1971) en sus comentarios sobre el trabajo de Moskvin, un experimentado actor del TAM, quien: "no se olvida de si mismo", "observa una actitud irónica y escéptica", "exagera su papel y denigra a su personaje, porque sabe que interpreta el papel de un canalla", con lo que "desenmascara a su personaje" (p. 265). Todo esto nos sitúa ante la relación entre Meyerhold y Brecht, que no abordaremos, si bien diremos que, como señala Fuegi (1973)

it is clear that a full decade before the Russian Revolution and before Brecht had even entered his teens, a number of technical devices we in the West tend to associate with Brecht and Piscator and the epic theater were in use in Russia [queda claro que toda una década antes de la Revolución Rusa y antes de que Brecht hubiese siquiera llegado a la adolescencia, diferentes medios técnicos, que nosotros en el este solemos asociar con Brecht o Piscator y el teatro épico, estaban en uso en Rusia]. (1973, p. 104)6

Entre esos mecanismos no podemos olvidar el arte del actor. Tal vez ese sea uno de sus más importantes aportes, al señalar que el arte en su artificialidad no imita la realidad, sino que la construye (Jestrovic, 2002, p. 45). De esta forma, está señalando una vía de trabajo nueva en la construcción del personaje, plenamente acorde con su idea del espectador y de la comunicación teatral. En efecto, Meyerhold escribió en 1933 que: "la biomecánica es un sistema de adiestramiento" del actor que busca "movilizar todos los medios a su disposición y los conduzca al espectador, de manera que las ideas fundamentales del espectáculo puedan llegar al público" (1971, p. 263). Un reto todavía presente en los teatros de hoy, y todavía más en el ámbito de la formación teatral en la que sigue predominando la escuela inductiva abonada al dolor, "al rascuño y al mascullar" (Hayes, 1999). La misma que fue denunciada en su misma cuna por Richardson (1999). Una escuela inductiva que se sitúa bien lejos del juego del "como sí" que propone Brook (1995) y que ya prefiguraba Meyerhold (Baldwin, 1995; Baldwin \& Syssoeva, 1999; Normington, 2005). Por eso, es hora de volver los ojos a las enseñanzas de un maestro imperecedero.

${ }^{6}$ Eaton (1977) ofrece información interesante sobre esa influencia. 


\section{Referencias}

Abensour, G. (1998). Vsévolod Meyerhold ou l'invention de la mise en scène. Paris: Fayard.

Arlander, A., Gröndahl, L., \& Sildee, M. (2016). Textures of Theatricality: Three Approaches from Canonical Theatre Directors. In Tekijä - teos, esitys ja yhteiskunta. Näyttämö \& tutkimus, 6, 60-85.

Aston, E. \& Savona, G. (1991). Theatre as sign-system. A Semiotics of Text and Performance. London: Routledge.

Baldwin, J. (1995). Meyerhold's Theatrical Biomechanics: An Acting Technique for Today. Theatre Topics, 5(2), 181-201.

Baldwin, J. \& Syssoeva, K. M. (1999). La biomécanique de Meyerhold et l'acteur contemporain: comment former l'acteur complet. L'Annuaire théâtral, 25, 134-150.

Barris, R. (2013). The Life of the Constructivist Theatrical Object. Theatre Journal, 65(1), 57-76.

Barthes, R. (1973). Ensayos críticos. Barcelona: Seix Barral.

Bennett, S. (1997). Theatre audiences. New York: Routledge.

Berger, P. L. \& Luckmann, T. (1986). La construcción social de la realidad. Buenos Aires: Amorrortu.

Birringer, J. (1991). Theatre, Theory, Postmodernism. Bloomington: Indiana University Press.

Blanck, G. (1990). Vygotsky: The man and his cause. En L. C. Moll (Ed.), Vygotsky and Education. Instructional implications and applications of Sociohistorical Psychology (pp. 31-58). Cambridge: Cambridge University Press.

Braun, E. (1969). Meyerhold on Theatre. London: Methuen.

Braun, E. (1986). El director y la escena. Del naturalismo a Grotowski. Buenos Aires: Galerna.

Braun, E. (2006). Meyerhold: A Revolution in Theatre. London: Methuen.

Brook, P. (1995). There are no Secrets. London: Methuen Drama.

Bunge, M. (2002). Crisis y reconstrucción de la filosofía. Barcelona: Gedisa.

Carlson, M. (1996): Performance. A critical introduction. New York: Routledge. 
Cuesta J. M. \& Jiménez J. (Eds.) (2005). Teorías literarias del siglo XX. Madrid: Akal.

De Micheli, M. (2002). Las vanguardias artísticas del siglo XX. Madrid: Alianza.

Diéguez, A. (2006). La ciencia desde una perspectiva postmoderna: Entre la legitimidad política y la validez epistemológica. En Actas de las /I Jornadas de Filosofía: Filosofía y política (pp. 177-205). Málaga: Procure.

Domínguez, J. (Ed.) (1997). Hermenéutica. Madrid: Arco Libros.

Eaton, K. (1977). Brecht's Contacts with the Theater of Meyerhold. Comparative Drama, 11(1), 3-21.

Eaton, K. B. (1985). The Theatre of Meyerhold and Brecht. Westport, CT: Greenwood Press.

Eikhenbaum, B. (2005). La teoría del método formal. En J. M. Cuesta Abad \& J. Jiménez Heffernan (Eds.), Teorías literarias del siglo XX (pp. 51-66). Madrid: Akal.

Elam, K. (2002). The Semiotics of Theatre and Drama. London: Routledge.

Erlich, V. (1974). El formalismo ruso. Barcelona: Seix Barral.

Fischer-Lichte, E. (1997). The Show and the Gaze of theatre. A European Perspective. lowa City: University of lowa Press.

Fuchs, G. (1959). Revolution in the Theatre: Conclusions Concerning the Munich Artists' Theatre. Ithaca, Nueva York: Cornell University Press.

Fuchs, G. (1992). La revolución del teatro. En E. Ceballos (Ed.), Principios de dirección escénica (pp. 207-214). México: Escenología.

Fuegi, J. (1973). Russian "Epic Theatre" Experiments and the American Stage. Minnesota Review, 1, 102-112.

Funtowicz, S. O. \& Ravetz, J. R. (2000). La ciencia posnormal. Barcelona: Icaria.

Gan, A. (2014). El constructivismo. Barcelona: Editorial Tenov.

Gassner, H. (1992). The Constructivists: Modernism on the Way to Modernization. En The Great Utopia. The Russian and Soviet Avant-Garde (pp. 289-319). New York: Guggenheim Museum.

Goldberg, R. (1988). Performance Art: From Futurism to the Present. London: Thames \& Hudson.

Gray, C. (1962). The Great Experiment: Russian Art 1863-1922. New York: Harry N. Abrams. 
Habermas, J. (1986). Ciencia y técnica como "ideología". Madrid: Tecnos.

Harrison, G. R. \& Marquardt, V. H. (1992). The Avant-Garde Frontier: Russia Meets the West, 1910-1930. Gainesville, FL: University Press of Florida

Hayes, H. (1999). Prólogo. En D. Richardson, Interpretar sin dolor. Una alternativa al Método (pp. 51-54). Madrid: Publicaciones de la ADE.

Hessels, L. K. \& Lente, H. van (2008). Re-thinking new knowledge production: A literature review and a research agenda. Research Policy, 37, 740-760.

Hoover, M. L. (1974). Meyerhold: The Art of Conscious Theater. Amherst: University of Massachusetts Press.

Hormigón, J. A. (1971). Introducción a la dramaturgia meyerdoldiana. En V. Meyerhold, Textos teóricos I (pp. 27-97). Madrid: Alberto Corazón.

Hormigón, J. A. (2017). El teatro y la revolución de octubre. ADE/Teatro, 166, 20-43.

Iglesias, M. (1994). La estética de la recepción y el horizonte de expectativas. En D. Villanueva (Comp.), Avances en teoría de la literatura (pp. 35-115). Compostela: Universidad de Santiago.

Ingarden, R. (1989). Concreción y reconstrucción. En R. Warning (ed.), Estética de la recepción (pp. 35-53). Madrid: Visor.

Iser, W. (1987). El acto de leer. Madrid: Taurus.

Javier, F. (2009). Supervivencia de Meyerhold. Cuadernos del Picadero, 18, Presencia de Vsévolod Meyerhold, 4-11. Recuperado de: http://inteatro.gob.ar/Files/Publicaciones/15/18.pdf

Jelavich, P. (1985). Munich and Theatrical Modernism: Politics, Playwriting, and Performance, 1890-1914. Cambridge: Harvard University Press.

Jiménez-Buedo, M. \& Ramos Vielba, I. (2009). ¿Más allá de la ciencia académica? Modo 2, ciencia posacadémica y ciencia posnormal. Arbor, 738, 721-737.

Jestrovic, S. (2002). Theatricality as Estrangement of Art and Life in the Russian Avant-garde. SubStance, 31(2/3), 42-56.

Kirikov, B. \& Vallye, A. (2008). The Leningrad Avant-Garde and Its Legacy. Future Anterior, 5(1), 16-26.

Kleberg, L. (1993). Theatre as Action. Soviet Russian Avant-Garde Aesthetics. London: MacMillan. 
Kowzan, T. (1997). El signo en el teatro. En M. C. Bobes Naves (Ed.), Teoría del teatro (pp. 121-153). Madrid: Arco Libros.

Kuhn, T. (1975). La estructura de las revoluciones científicas. Madrid: Fondo de Cultura Económica.

Leach, R. (1993). Vsevolod Meyerhold (Directors in Perspective). Cambridge: Cambridge University Press.

Leach, R. (2004). Makers of modern Theatre. An introduction. London: Routledge.

Leontiev, A. N. (2006). Introducción. En L. Vygotsky, Psicología del arte (pp. 13-20). Barcelona: Paidós.

Lepecki, A. (2006). Exhausting dance: performance and the politics of movement. New York: Routledge.

Lledó, E. (1985). Literatura y crítica filosófica. En J. M. Díez Borque (Ed.), Métodos de estudio de la obra literaria (pp. 419-464). Madrid: Taurus.

López, R. (2010). Por una conceptualización del constructivismo. Revista Mad, 23, 25-30.

Mally, L. (1990). Culture of the Future. The Proletkult Movement in Revolutionary Russia. Berkeley: University of California Press.

Markov, V. (1968). Russian Futurism. A History. Berkeley: University of California Press.

Martín, M. (2004). Teoría de la comunicación: una propuesta. Madrid: Tecnos.

Mayoral, J. A. (Ed.) (1987). Estética de la recepción. Madrid: Arco Libros.

Mayoral, J. A. (Ed.). (1999). Pragmática de la comunicación literaria. Madrid: Arco Libros.

Meyerhold, V. (1971). Textos teóricos I. J. A. Hormigón (Ed.). Madrid: Alberto Corazón.

Meyerhold, V. (1972). Textos teóricos II. J. A. Hormigón (Ed.). Madrid: Alberto Corazón.

Meyerhold, V. (2010). Lecciones de Dirección Escénica (1918-1919). J. Saura (Ed.). Madrid: Publicaciones de la ADE.

Mueller, R. (1987). Montage in Brecht. Theatre Journal, 39(4), 473-486.

Normington, K. (2005). Meyerhold and the New Millennium. New Theatre Quarterly, 21(2), 118-126.

Pitches, J. (2003). Vsevolod Meyerhold. London: Routledge. 
Perone, E. (2015). L'Avvenimento teatrale come festa. La prima teoria teatrale di Georg Fuchs. Spazio Filosofico, 14, 221-232.

Radunovic, D. (2015). On "Secondary Aesthetics, Without Isolation": Philosophical Origins of Mikhail Bakhtin's Theory of Form. The Slavic and East European Journal, 59(1), 1-22.

Richardson, D. (1999). Interpretar sin dolor. Una alternativa al Método. Madrid: Publicaciones de la ADE.

Sánchez, J. M. (2014). Dramaturgias de la imagen. Cuenca: Universidad de Castilla La Mancha.

Sanchis, Sinisterra, J7. (1995). Por una dramaturgia de la recepción. ADE/Teatro, 41-42, 6469.

Sauter, W. (2000). The Theatrical Event: Dynamics of Performance and Perception. lowa: University of lowa Press.

Schechner, R. (2002). Performance. An introduction. Nueva York: Routledge.

Scheinin, N. A. (2009). Meyerhold en el umbral del tiempo. Cuadernos del Picadero, Presencia de Vsévolod Meyerhold 18. 41-51 Recuperado de: http://inteatro.gob. ar/Files/Publicaciones/15/18.pdf

Segel, H. (1987). Turn-Of-The-Century Cabaret: Paris, Barcelona, Berlin, Munich, Vienna, Cracow, Moscow, St. Petersburg, Zurich. Nueva York: Columbia University Press.

Senelick, L. (1981). Russian dramatic theory from Pushkin to the Symbolists: an anthology. Austin, TX: University of Texas Press.

Shklovski, V. (2005). El arte como artificio. En J. M. Cuesta Abad y J. Jiménez Heffernan (Eds.), Teorías literarias del siglo XX (pp. 68-73). Madrid: Akal.

Stanislavski, K. (2013). Mi vida en el arte. Barcelona: Alba.

Styan, J. L. (1981). Modern drama in theory and practice, 3. Expressionism and Epic Theatre. Cambridge: Cambridge University Press.

Tian, M. (2012). Mei Lanfang and the Twentieth-Century International Stage: Chinese Theatre Placed and Displaced. Nueva York: Palgrave Macmillan.

Vieites, M. F. (2008). El personaje dramático a la luz de las grandes corrientes del pensamiento. Notas dispersas. En J. A. Hormigón (Ed.), Del personaje literario-dramático al personaje escénico (pp. 259-289). Madrid: Publicaciones de la ADE. 
Vieites, M. F. (2016). Teatro y comunicación. Un enfoque teórico. Signa. Revista de la Asociación Española de Semiótica, 25, 1153-1178.

Vieites, M. F. (2017). El teatro vacío. Manual de política teatral. Madrid: Publicaciones de la ADE.

Vygotsky, L. (2006). Psicología del arte. Barcelona: Paidós.

Warning, R. (Ed.). (1989). Estética de la recepción. Madrid: Visor.

Zalambani, M. (1998). L'arte nella produzione. Avanguardia e rivoluzione nella Russia soviética degli anni '20. Rávena, Italia: Longo E 